\title{
Green and Environmental Protection Recycled Concrete in Road Engineering
}

\author{
Yulong Ma, ${ }^{1}$ Yongcheng Ji ${ }^{1},{ }^{1}$ and Lei Jin ${ }^{2}$ \\ ${ }^{1}$ College of Civil Engineering, Northeast Forestry University, Harbin 150040, China \\ ${ }^{2}$ College of Economics and Management, Tianjin University, Tianjin 300000, China
}

Correspondence should be addressed to Yongcheng Ji; yongchengji@nefu.edu.cn

Received 11 December 2021; Revised 3 January 2022; Accepted 21 January 2022; Published 15 February 2022

Academic Editor: Punit Gupta

Copyright (c) 2022 Yulong Ma et al. This is an open access article distributed under the Creative Commons Attribution License, which permits unrestricted use, distribution, and reproduction in any medium, provided the original work is properly cited.

In response to a series of national strategic guidelines for green and sustainable development, recycled concrete is used as a recyclable resource. First, the mechanical properties, workability, and durability of recycled concrete are briefly introduced, and the benefit and necessities of research on recycled concrete are described from environmental, economic, and social perspectives. Second, the mixing method and molding process of recycled concrete are described in detail, and the influence of vibration molding and compression molding on the performance of recycled concrete is analyzed. It is found that the compressive strength first increases and then decreases with the increase of molding pressure. In addition, porosity decreases as molding pressure buildup. Therefore, it is recommended that the molding pressure of recycled concrete be generally controlled between 600 and $800 \mathrm{~N}$. Then, the influence of the water-cement ratio on recycled concrete's fluidity and mechanical properties is discussed. It is found that with the increase of the water-cement ratio, the compressive strength first increases and then decreases and the optimum water-cement ratio is proposed to be 0.2 . Finally, the application status and problems of recycled concrete in road engineering are briefly described, and relevant suggestions for construction technology are put forward. Based on the fire safety and reliability requirements of concrete structures, the performance of high-performance concrete structures after fire can be restored to the initial level or even improved through the processes and measures of building structure design, repair, and reinforcement; the strength and crack healing of high-performance concrete after fire can be gradually restored by applying or soaking repair agent and water curing; the recovery of $\mathrm{pH}$ value of concrete after fire and the reduction of carbonation depth can be realized by using electrochemical realkalization technology; using carbon fiber to strengthen the components after fire can restore the bearing capacity, but the degree of stiffness recovery is low; and beam side steel plate reinforcement and steel bonding reinforcement can realize the recoverability of bearing capacity, stiffness, and ductility of members after fire.

\section{Introduction}

For decades, China's economic development has made remarkable achievements, and people's basic survival needs have been satisfied already. Since then, people have begun to pay more attention to the quality of life and pursue green development and a healthy lifestyle. Energy conservation, environmental protection, and sustainable development have become the focus of society in this context. However, much construction waste will be generated in traditional road construction, and abandoned concrete is one of them. This phenomenon is contrary to the concept of environmental protection and sustainability, taken seriously by the industry and the country. Therefore, a technology for making green and environmental-friendly recycled concrete from abandoned concrete and reusing it for road engineering construction has been widely studied and applied [1].

The research shows that the demand for recycled coarse aggregate exceeds the supply of waste concrete, indicating that the market prospect of recycled coarse aggregate is broad [2]. Huang et al. [3] studied the effect of recycled coarse aggregate gradation on the shear behavior of recycled concrete and found that the shear strength of well-graded recycled coarse aggregate is greater than that of poorly graded and discontinuous graded recycled coarse aggregate. 
Xiong et al. [4] studied the mechanical properties of recycled concrete with different coarse aggregate substitution rates and put forward the prediction formula of compressive strength. Liang et al. [5] studied the effect of different coarse aggregate substitution rates on hysteretic energy and found that hysteretic energy increased with the coarse aggregate substitution rate increase. Wajeeha et al. [6] studied the durability of recycled concrete with different replacement rates of recycled coarse aggregate in a chloride environment. Through the pull-out test, it is found that $30 \%$ of natural coarse aggregate concrete can be used as structural concrete in Pakistan's construction sector. Zhang et al. [7] studied the mechanical properties of recycled concrete with the replacement rate of a recycled coarse aggregate of $0 \%, 25 \%$, $50 \%, 75 \%$, and $100 \%$, respectively. The results show that with the increase of the replacement rate of recycled coarse aggregate, the mechanical properties of concrete show a linear downward trend. Therefore, it is concluded that the amount of recycled coarse aggregate in road construction should not exceed $50 \%$, considering the dry shrinkage and temperature shrinkage test results. Xie et al. [8] studied cast-in situ recycled aggregate concrete's mechanical properties and durability under chemical sulfate attack, prepared concrete cylinders with recycled concrete aggregates of $0 \%, 30 \%, 50 \%$, and $100 \%$, respectively. They found that recycled concrete aggregates have a significant impact on the mechanical properties of concrete. Marian et al. [9] prepared recycled concrete with the replacement rate of a recycled coarse aggregate of $50 \%$ and $100 \%$, respectively. Three specimens with different curing periods ( 7,14 , and 28 days) were tested. The results show that with the increase of recycled aggregate content, the compressive strength and flexural strength of all recycled concrete decrease, while the density is slightly affected. Kashkash saied et al. [10] prepared four mixtures using recycled concrete aggregate and recycled crushed aggregate as natural coarse aggregate substitutes with different replacement percentages. A series of tests were carried out to study the characteristics of fresh and hardened concrete samples prepared from mixtures of various components. The results show that recycled concrete with recycled aggregate instead of 50\% natural coarse aggregate can have sufficient fresh and hardening properties. Although the compressive strength of recycled concrete is higher than that of conventional concrete, the workability of recycled concrete mix proportion decreases significantly.

All of above studies are conducted. However, the benefits and properties of recycles concrete are not clear. The procedure and methodology of recycled concrete construction need to be further investigated.

\section{Property Characteristics of Green and Environmental-Friendly Recycled Concrete}

Although green recycled concrete is economically and environmentally friendly, its relevant property cannot be comparable to that of ordinary concrete due to the process of rebuilding after crushing abandoned concrete and is one grade worse than that of ordinary concrete. Therefore, before road engineering application, it is necessary to study its property characteristics in detail. Furthermore, the preparation process of green recycled concrete should be selected according to different requirements in specific road construction [11].

2.1. Mechanical Properties. The application characteristics of concrete material in road engineering require that concrete material have a specific bearing capacity, mainly reflected by its mechanical properties. The mechanical properties of green environmental-friendly concrete are related to its breaking method of recycled aggregate, the strength of abandoned concrete, water-cement ratio, and specific construction environment [12]. According to the research, the strength of recycled concrete is inversely proportional to the replacement rate of recycled aggregate, positively proportional to the water-binder ratio, and positively proportional to the strength of abandoned concrete. The smaller the replacement rate of recycled aggregate, the greater the strength; the higher the waterbinder ratio, the stronger the strength, and the stronger the abandoned concrete is, the stronger the recycled concrete will be.

2.2. Workability. The workability of green recycled concrete is related to the replacement rate of recycled aggregate and the water-binder ratio. Compared with ordinary concrete, recycled concrete is made of abandoned concrete after crushing, and the surface of recycled aggregate is so rough that the water absorption performance is more significant than ordinary concrete. Consequently, the slumps of recycled concrete are smaller than that of ordinary concrete with similar conditions. Specifically, the slumps of recycled concrete are inversely proportional to the content of recycled concrete and are positively proportional to its water-binder ratio, that is, the less recycled aggregate, the greater the slumps of recycled concrete; and the smaller the waterbinder ratio is, the smaller the slumps of recycled concrete is [13].

2.3. Durability. For all concrete materials, durability is a crucial property index, which determines the severity of the application environment of concrete materials and the service life of the concrete. Under normal circumstances, compared with two kinds of concrete materials with similar conditions, recycled concrete has better crack resistance, but its freeze-thaw resistance and permeability resistance are not as good as ordinary concrete materials [14]. For recycled concrete, its permeability resistance can be improved by adding fly ash, and its freeze-thaw resistance can be improved by reducing its water-binder ratio. However, improving the property of recycled concrete will inevitably lead to the increase of its preparation cost, which requests the engineers to select the optimal balance point according to the application requirements of road engineering and the comprehensive consideration of cost. 


\section{Benefits of Recycled Concrete Applied in Road Engineering}

3.1. Environmental Benefits. At present, the abandoned concrete generated in the construction of domestic road engineering is mostly stacked in the open air, occupying many land resources, which pollutes the urban environment and harms the urban landscape, and causes a massive waste of resources. In addition, during the handling and stacking of abandoned concrete, problems such as dust raising will occur, aggravating environmental pollution. Therefore, recycling abandoned concrete during road construction can save resources, protect the environment, and significantly contribute to China's energy saving and environmental protection.

3.2. Economic Benefits. In the construction of a new road project or road widening and rebuilding project, many concrete materials are generally required. Stone concrete is one of the indispensable materials. However, stones are often unavailable locally and need to be transported from tens of kilometers, resulting in higher transportation costs, which directly increases the production cost of concrete materials. At this point, the economic value of recycled concrete and be highlighted. In road engineering construction, if the abandoned concrete is reused and processed into concrete aggregate, it can reduce the transportation cost of stone and reduce the material cost of stone, thus reducing the cost of concrete. Furthermore, it is worth noting that a large amount of abandoned concrete will be generated when repairing the pavement of a high-grade highway, which has few impurities and can be used for processing and making concrete aggregate instead of stone. In a word, the recycling of abandoned concrete in road engineering can reduce the cost of concrete to a great extent and has significant economic value.

3.3. Social Benefits. The Chinese government has paid much more attention to energy conservation, environmental protection, and resource reuse in recent years. In this context, recycled concrete in road engineering construction is a reform and innovation of road construction technology and can promote the sustainable development of China's basic transportation construction.

\section{Study on Preparation Technology of Recycled Concrete}

Unlike ordinary concrete, recycled concrete is a uniquely functional building material with a porous structure composed of a layer of cement slurry on the surface of coarse aggregates. The improper preparation process will result in uneven pore distribution and an increased proportion of discontinuous pores in concrete [15]. Therefore, unique methods and techniques should be adopted during mixing, molding, and maintaining.
4.1. Research on the Mixing Process. The mixing process of ordinary concrete usually adopts a mixing method, which is easy enough to operate. However, recycled concrete belongs to stiff concrete, and there is no ball effect produced by fine aggregate during the mixing process. Therefore, the high resistance and the coarse aggregates are very vulnerable to crushing. Moreover, improper mixing sequence and charging sequence will result in slurry aggregation, significantly reducing the proportion of connected porosity of recycled concrete. Consequently, it is of great significance to study the mixing process of recycled concrete.

The mixing method in this paper refers to the wrapped slurry process, which significantly improves the property of recycled concrete by changing the order of raw materials' charging sequence and significantly increases the proportion of connected porosity in concrete on the premise of the high strength of recycled concrete. Specific steps are as follows: First, add all the coarse aggregates and 50\% water into the mixer and stir for 30 seconds, which can clean the aggregate surface and avoid forming weak areas between the cement slurry and the coarse aggregates. Moreover, wetting the surface can increase the bonding effect with the cement; second, $100 \%$ cement, water, and additives are added and stirred for 180 seconds. In this way, the aggregate surface is evenly coated with a high flow slurry, which can significantly reduce the friction between the aggregate, thus preventing the crushing of coarse aggregate due to excessive resistance. Moreover, the slurry is evenly wrapped on the surface of coarse aggregate, making it further spheroid [16]. The spheres bond with each other from point to point and surface to surface. As a result, the proportion of concreteconnected porosity is significantly increased under the premise of the high strength of recycled concrete.

4.2. Research on the Molding Process. Coarse aggregates account for about $60 \%$ of the recycled concrete, and the friction between them is so great that the compactness of the structure cannot be satisfied only by rodding. On the other hand, standard molding methods mainly include vibration molding and compression molding. Therefore, it is essential to study the influence of the mentioned two methods on the property of recycled concrete.

4.2.1. Influence of Vibration Molding on Properties of Recycled Concrete. Recycled concrete was prepared from coarse aggregate with a single-particle size of $9.5-16 \mathrm{~mm}$, with a water-cement ratio of 0.20 and a cement-aggregate ratio of $1 / 6$. The fresh concrete is loaded in three layers into the mold of $100 \times 100 \times 100 \mathrm{~mm}^{3}$, and the thickness of each layer should not be more than $5 \mathrm{~mm}$, inserting from all sides to the center screw for at least 15 times with the $25 \mathrm{~mm}$ ramming rod. Then, the connected mold of the specimen was placed on the vibration table for 0-SC, respectively, and put into the standard curing room later. After 1 day, the specimen was demolded and put back into the stand curing room for 3 days and 28 days. The strength and porosity of recycled concrete with different vibration times are tested, respectively [17]. 
Figures 1 and 2 show the influence of vibration time on recycled concrete's compressive strength and porosity. It can be seen that with the increase of vibration time, the porosity of recycled concrete gradually decreases, while the strength first increases and then decreases. When the time remains about $8 \mathrm{~s}$, the strength reaches its maximum value. It is mainly because of the increase of vibration time. The aggregates become more and more compact from the loose deposit under the vibration. Moreover, the aggregate is bonded point to point and surface to surface, producing an effect of mechanical bit [18], so the compressive strength is obviously higher than that of nonvibration recycled concrete. However, with the accumulation of the vibration time, the cement slurry wrapped in the aggregate surface slides and densely distributes at the bottom of the concrete. As a result, the slurry volume on the concrete upper part and the bonding area between the aggregates decreases, which leads to the decline of the overall compressive strength of recycled concrete. The cement slurry concentrated at the bottom of concrete forms a dense layer (shown in Figures 1 and 2), which seriously affects the connectivity between the upper and lower layers of recycled concrete. However, the vibration time is related to the water-cement ratio and the amount of slurry used, so the specific engineering test should determine the specific vibration time.

4.2.2. Influence of Compression Molding on Properties of Recycled Concrete. Due to the high viscosity of fresh mixed recycled concrete, it cannot be fully compacted by mechanical vibration only. Therefore, in addition to vibration molding, compression molding is mainly used in China. After the fresh concrete is loaded in three layers into the mold of $100 \times 100 \times 100 \mathrm{~mm}^{3}$, pressure is applied to the surface to promote the compactness of the whole structure of recycled concrete [19]. The raw materials and mix ratio used in this test are the same as that of vibration molding, but the molding pressure is changed to $400 \mathrm{~N}-1000 \mathrm{~N}$ during the molding process, lasting for 5 seconds. The test results are shown in the following figure.

Figures 3 shows the influence of molding pressure on recycled concrete's compressive strength and porosity. It can be seen from Figure 4 that the relationship between molding pressure and compressive strength is not simply linear. With the increase of molding pressure, the compressive strength increases first and then decreases, while the porosity decreases continuously with the accumulation of molding pressure. It is mainly due to the volume compression of the loose concrete after the press pours ramming at the beginning. As a result, the volume of recycled concrete changes, the porosity is constantly reduced, and the aggregate is more closely combined, so the compressive strength shows a rising trend. However, when the molding pressure increases to a certain extent, the aggregate is in closed contact with each other, and the volume of recycled concrete cannot be further reduced. At this time, a continuous increase of pressure may cause damage to the contact point or aggregate, leading to the decline of the

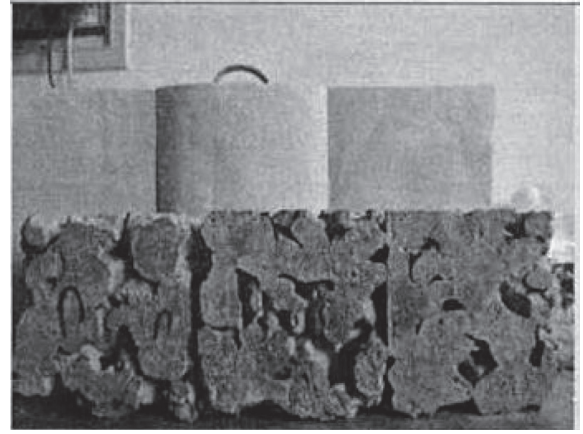

FIgURE 1: Overlong vibration time.

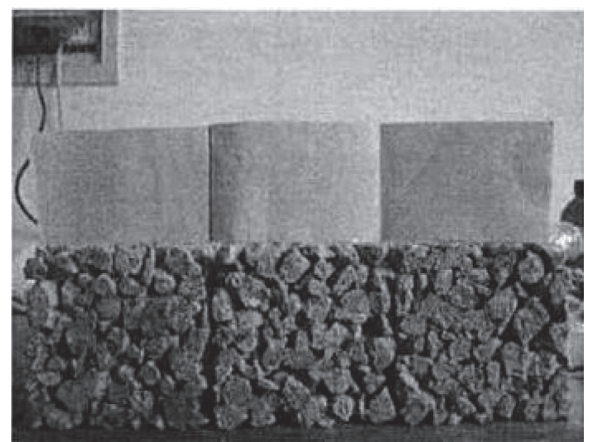

Figure 2: Proper vibration time [17].

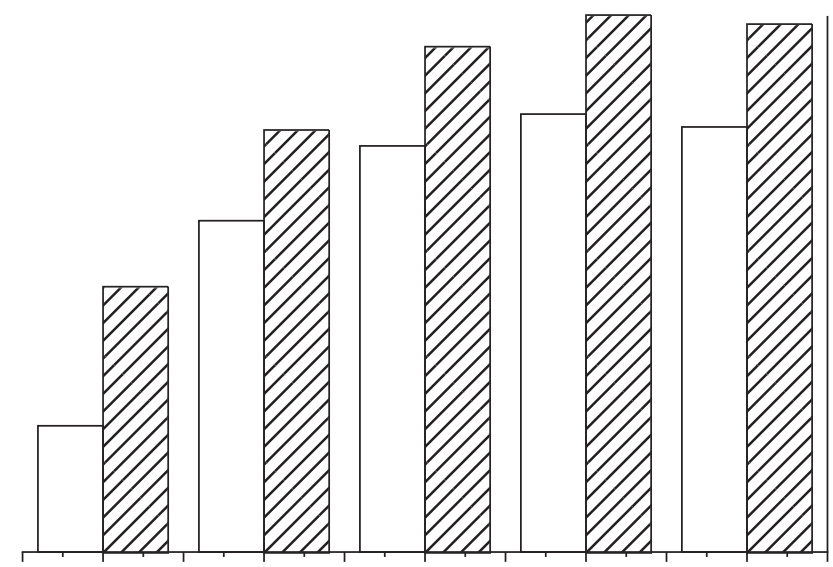

FIGURE 3: Effect of molding pressure on compressive strength.

compressive strength. Therefore, the molding pressure of concrete is generally controlled between 600 and $800 \mathrm{~N}$ [20].

Improper selection of molding technology is likely to cause uneven pore distribution and an increase of discontinuous pore in concrete. In order to verify the rationality of the combined molding process of vibration molding and compression molding [21], a cylindrical recycled concrete specimen with a size of $110 \mathrm{~mm} \times 150 \mathrm{~mm}$ was prepared with $9.5-16 \mathrm{~mm}$ single-particle aggregates in this test. The axial plane porosity distribution of recycled concrete when vibration time is 8 seconds, and molding pressure remains $800 \mathrm{~N}$ combined with CT scanning technology. 

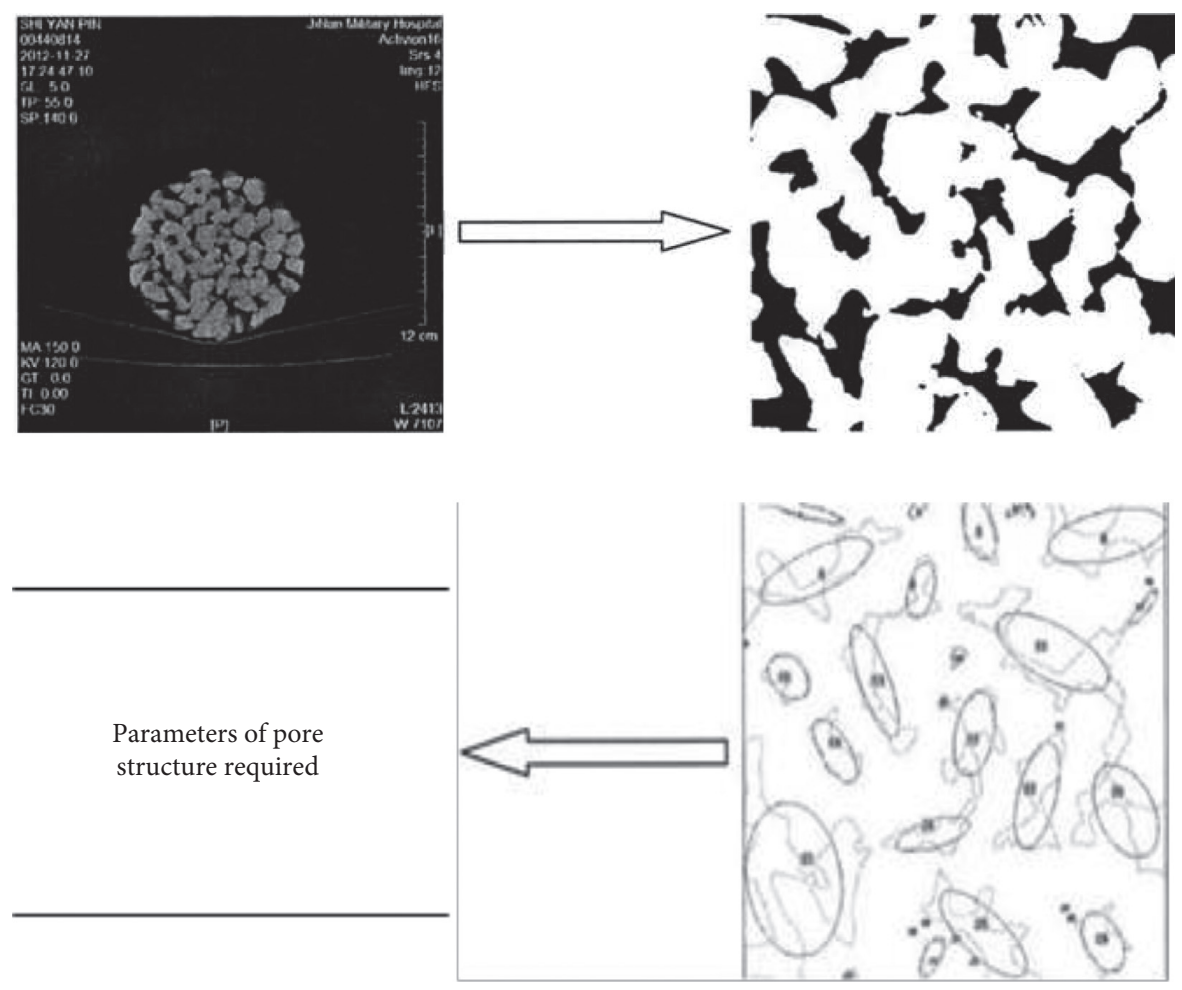

FIGURE 4: Scanned image processing schematic diagram [18].

\section{Influence of Water-Cement Ratio on Properties of Recycled Concrete}

The water-cement ratio is an essential parameter for recycled concrete, which determines the workability of the concrete and has a specific influence on its compressive strength, pore structure, and permeability performance. The appropriate water-cement ratio is the first step to prepare recycled concrete successfully [22]. So far, there is no specific method to determine the water-cement ratio in China. The crushed basalt with a $9.5-16 \mathrm{~mm}$ particle size was selected in this test to prepare the recycled concrete with the cement-aggregate ratio of $1 / 6$ and the water-cement ratio of $0.18-0.24$ [23]. Moreover, standard maintenance is carried out by artificial ramming, vibration, and compression. The influence of water-cement ratio on recycled concrete's compressive strength and porosity for 3 and 28 days is discussed. The results are shown in the table below.

It can be seen from Table 1 that for a particular cement, there is an optimum water-cement ratio under the same aggregate gradation, cement-aggregation ratio, and molding curing process. The compressive strength of recycled concrete shows an upward trend when the water-cement ratio increases from 0.18 to 0.20 . This is mainly due to the low water-cement ratio, easy agglomeration of slurry, and uneven wrapping of aggregate surface, so that the friction between them increases significantly, and the strength is relatively low because of insufficient stirring. While the water-cement ratio is more than 0.20 , the slurry will slide off the aggregate and deposit at the bottom of the concrete due to its own gravity during the preparation of recycled concrete. This not only results in a significant reduction of the cementing materials on the upper part of concrete, different compactness of test block on the upper and lower sides, and a reduction of overall compressive strength but also enriches cement slurry on the bottom of recycled concrete [24], forming a dense cement slurry layer, which seriously affects the connectivity of pore. When the watercement ratio is 0.20 , the fluidity of cement slurry is moderate, and the aggregate surface is evenly coated with a layer of slurry. Therefore, the overall structure is stable enough. Moreover, the compressive strength for 3 days and 28 days of concrete is $12.46 \mathrm{MPa}$ and $13.85 \mathrm{MPa}$, respectively.

The influence of fluidity on mechanical properties and porosity of recycled concrete was discussed by measuring the slurry fluidity under different water-cement ratios with reference to test method for fluidity of cement mortar (GB2419) [25]. It can be seen from Table 1 and Figure 5 that the watercement ratio determines the fluidity of slurry, whereas the fluidity determines the uniformity of concrete aggregate coating. When the water-cement ratio is less than 0.18 , the slurry fluidity is less than $170 \mathrm{~mm}$, and the slurry is rugged and easy to agglomerate. Moreover, the aggregate cannot be evenly wrapped. As a result, the fresh concrete is loose, dry, and dull. When the water-cement ratio is $0.18-0.22$, the fluidity of slurry is between $170 \mathrm{~mm}$ and $220 \mathrm{~mm}$, and the appearance of freshly mixed concrete is improved, with the slurry of good cohesion. However, when the water-cement ratio is more than 0.22 , the fluidity is more than $220 \mathrm{~mm}$, and the fresh concrete slurry flows, with the aggregate of poor cohesion. At this time, the slurry will settle to the bottom of the specimen due to its own weight, which will result in partial or complete blockage of the 
TABLE 1: Effect of water-cement ratio on slurry fluidity and porous ecological concrete properties.

\begin{tabular}{lccccc}
\hline $\begin{array}{l}\text { Water-cement } \\
\text { ratio }\end{array}$ & $\begin{array}{c}\text { Mortar fluidity } \\
(\mathrm{Imm})\end{array}$ & $\begin{array}{c}\text { Cement-aggregate } \\
\text { ratio }\end{array}$ & $\begin{array}{c}\text { Aggregate size } \\
(\mathrm{mm})\end{array}$ & $\begin{array}{c}\text { Compressive strength for 28 d } \\
(\mathrm{MPa})\end{array}$ & $\begin{array}{c}\text { Porosity } \\
(\%)\end{array}$ \\
\hline 0.18 & 168.3 & $1 / 6$ & $9.5-16$ & 6.16 & 28.57 \\
0.20 & 207.5 & $1 / 6$ & $9.5-16$ & 12.46 & 28.01 \\
0.22 & 219.6 & $1 / 6$ & $9.5-16$ & 9.89 & 27.44 \\
0.24 & & $1 / 6$ & $9.5-16$ & 7.33 & 27.13 \\
\hline
\end{tabular}

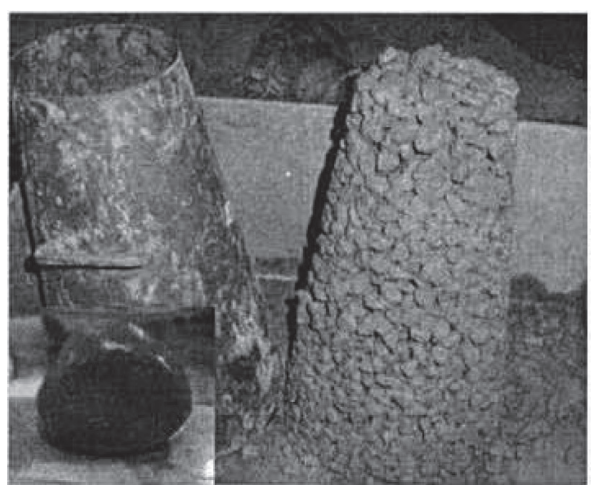

$(0.20)$

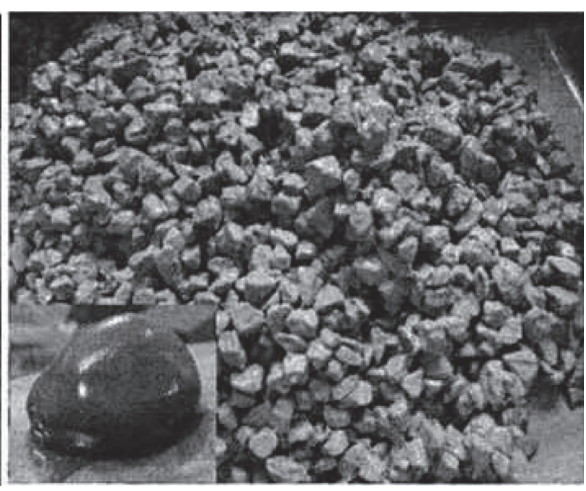

$(0.24)$

Figure 5: Slurry coating aggregate when water-cement ratio is 0.20 and 0.24 , respectively [25].

pore at the bottom of the concrete, and the permeation coefficient will be greatly reduced. Therefore, the water-cement ratio of recycled concrete can be determined by measuring the fluidity of slurry in the mix design so that recycled concrete with both porosity and mechanical properties can be prepared. The water-cement ratio of sulphoaluminate brine slurry selected in this test should be controlled between 0.20 and 0.22 , and it is the best at 0.20 [26].

\section{Application Status and Existing Problems of Recycled Concrete in Road Engineering}

6.1. Application Status of Recycled Concrete in Road Engineering. Concrete is the most widely used material in road engineering construction. With the robust construction of highway projects and municipal road projects in China, many problems in natural resources, sustainable development, and environmental protection have arisen. Recycled concrete can be used in road construction requires two main premises: a. the continuous construction of road engineering needs a large number of concrete materials, which will inevitably consume a large number of natural resources and b. when widening and rebuilding the existing roads, there will be many abandoned concrete. This abandoned concrete occupies a considerable space in the processing but also causes some pollution to the environment. The above phenomena are not consistent with the basic policy of green and sustainable development in China, which leads to the imperative of using recycled concrete in road engineering to ensure the sustainable development of road engineering.

Nowadays, more and more road projects use recycled concrete in the construction process. However, when the road engineering pavement exceeds a specific operating time, the mechanical properties of bituminous concrete or cement concrete will deteriorate accordingly. Moreover, when traffic volume on the road exceeds its design level, the road surface will be more or less damaged. Therefore, in terms of the concrete pavement repair [27], the original concrete surface needs to be generally broken first, and then the base is repaired, and finally resurfaces the concrete by paving and rolling.

\subsection{Problems Existing in the Application of Recycled Concrete in Road Engineering}

6.2.1. The Insufficient Research Depth of Recycled Concrete. At present, green recycled concrete has not become a largescale application. One of the key reasons is that the current technical research depth is so insufficient that it cannot play a substantial role in supporting its engineering application from a technical perspective. After all, for practical engineering applications, the technology used must be rigorously and carefully verified to ensure the maturity and reliability of the technology. As for recycled concrete, due to the lack of investment in this area, related technical is problematic, resulting in the current technical research and engineering application of recycled concrete has not reached the depth of engineering application. This is also one of the essential bottlenecks hindering the rapid development of recycled concrete.

6.2.2. The Insufficient Standards Followed by the Application. So far, although some laws and regulations have given specific guidance and requirements for applying recycled concrete in road engineering construction, there are still some problems. On the one hand, to meet the laws and regulations of the quality and reliability, some technical 
details have to be too conservative due to its overall technology immaturity, resulting in an unavoidable cost waste. However, on the other hand, these laws and regulations are not systematic enough, and there is no clear and complete description and requirements for any technical problems in the practical application of recycled concrete. Therefore, it will result in the engineers being afraid to use it without precise specification [28]. Moreover, the investor is unwilling to use recycled concrete for the safety of its investment due to its immature technology.

6.2.3. The Limited Bearing Capacity of Recycled Concrete. In addition to the problems mentioned above, the limitations of properties are also one of the critical reasons that restrict the application range of recycled concrete. From the performance characteristics of recycled concrete in the previous section, it can be seen that under similar conditions, the properties of recycled concrete are generally worse than that of ordinary concrete. This weakness determines the upper limit of the practical application of recycled concrete in engineering, which is destined to be narrower than ordinary concrete. Many researchers are committed to promoting recycled concrete's performance and successfully generating some with strength and properties. However, in general, recycled concrete still has some limitations, restricting its wide application in road engineering.

\section{Construction of Recycled Concrete}

\subsection{Preparations.}

(a) Make a comprehensive investigation of the site environment before the construction begins and remove all obstacles that may hinder the normal construction, such as trees and isolation belts.

(b) Damages on the original pavement that this reconstruction cannot repair shall be effectively pretreated before it begins, and different types of damages should resort to different treatment methods:

(a) In terms of crushed and loose damage, if the depth is greater than the maximum depth of reconstruction, it is necessary to be dug and repaired

(b) In terms of deformation, based on the construction depth, if the depth reaches more than $30 \mathrm{~cm}$, it needs to be milling before reconstruction

(c) In terms of cracks, the causes should be figured out first, and the cracks should be properly handled before reconstruction if they are determined to have an impact

(c) Use the milling planer to drive the existing expansion joint. The front and rear ends are milled for 12 meters and 2-5 meters, respectively. The milling depth is consistent with the maximum depth of reconstruction, and then, the new mixture shall be used for paving. (d) Before formal construction, the feasibility should be determined through the construction of the test section, which should be more than 200 meters long, and representative. The construction scheme should be adjusted appropriately accordingly to the results of the test section to ensure the effect of reconstruction.

7.2. Pavement Sweeping and Lining. The pavement surface should be carefully swept before construction to avoid debris and garbage mixed into the mixture. Then draw lines outside the edge of the reconstruction. Of course, the original road surface edge can also be directly used as the baseline of the reconstruction to ensure the aesthetics and straightness of the edge.

7.3. Heating of the Original Road Surface. The original road surface must be heated before the reconstruction. Otherwise, the aggregate will be damaged in raking, thus affecting the quality of construction. At the same time, it is also necessary to prevent the asphalt from aging in advance caused by very high heating temperature. The specific temperature is determined according to previous experience. Moreover, the width of heating needs to be widened by 20 centimeters on both sides, respectively, based on the milling range [29].

7.4. Raking of the Original Road Surface. The depth should be kept uniform while raking. However, if the depth must change, it shall change suddenly but not dramatically. By raking, the roughness of the surface is better, which can create good conditions for subsequent reconstruction. Moreover, it should be noted that the surface temperature should reach over $70^{\circ} \mathrm{C}$ when the raking is finished.

7.5. Spraying the Rejuvenation Agent. The rejuvenation agent should be sprayed with a particular device. Its walking needs to be linked with the remixer and realize the automatic control. It needs to be sprayed accurately according to the dose determined by design. Apart from that, the rejuvenation agent should also be heated before spraying to improve its fluidity and make it thoroughly fused with asphalt. The temperature needs to be controlled by the limited temperature that does not destroy its function. In addition, the actual amount of rejuvenation agent should be adjusted according to milling depth and its change [30].

7.6. Mixing and Paving. After completing the spraying of the rejuvenation agent and confirming that it meets the requirements of the remixer, use the machine to keep the mixture homogeneous. Then use a paver to spread the mixture evenly with a constant speed of $1.5-5.0 \mathrm{~m} / \mathrm{min}$. It is necessary to ensure the uniformity of the surface to prevent segregation, cracks, and galling. In addition, during construction, a particular person should be arranged to track and inspect the paving situation, and once problems are found, they should be dealt with immediately. Properly 
adjust the power of the screed according to the thickness of the reconstruction layer, make the paved mixture reach a good initial density, and reduce heat loss through the vibration of the screen. During paving, the temperature shall be strictly controlled within the range of $120-150^{\circ} \mathrm{C}$.

7.7. Rolling. After the paving is completed, a roller should be applied. There are two main types of rollers, including double-drum roller and pneumatic tyred roller. No matter what kind of roller is chosen, it should be closely followed by the paver in front, but pay attention to prevent collision with the paver. When the double-drum roller is used, appropriate amount of water can be sprayed on the surface in order to avoid that the mixture is bonded with the wheel. But the amount of water should be controlled, not too much to cause accumulation. However, while rolling by pneumatic tyred roller, spraying is generally not required [21]. And where large roller cannot reach, small machines and tools can be used for compaction manually.

7.8. Traffic Opening and Traffic Control. The mixture after compaction can be opened for traffic after natural cooling. However, attention should be paid to maintenance and management in that process, and personnel or vehicles are not allowed to enter. Otherwise, it will cause displacement, make the surface of the reconstruction layer uneven, and affect the subsequent application.

\section{Conclusion}

Engineering construction is developing continuously, and green environmental protection will be one of its essential requirements and characteristics. Three properties and benefits of green and environmentally friendly recycled concrete are summarized. First, the preparation technology of recycled concrete and the effect of the water-cement ratio are discussed. Then, the procedure of recycled concrete construction is presented after considering the application status and existing problems in recycled concrete road engineering. Thus, it is necessary to study recycled concrete technology to support road engineering construction's green, energy-saving, and sustainable development and accelerate its large-scale application in road engineering.

\section{Data Availability}

All data generated or analysed during this study are included in this published article.

\section{Conflicts of Interest}

The authors declare that they have no conflicts of interest.

\section{References}

[1] J. Song, "Discussion on the application of energy saving and environmental protection road recycled concrete," Green Environmental Protection Building Materials, vol. 19, no. 9, 2016.
[2] H. N. Han, I. Tomonori, R. Kubota et al., "Financial and economic evaluation of construction and demolition waste recycling in Hanoi, Vietnam," Waste Management, vol. 131, 2021.

[3] Y. Huang, J. Wang, M. Ying, J. Ni, and M. Li, "Effect of particle-size gradation on cyclic shear properties of recycled concrete aggregate," Construction and Building Materials, vol. 301, 2021.

[4] B. Xiong, D. Cristoforo, J. Xu, S. Alessandra, M. G. Carlo, and $\mathrm{X}$. Yan, "High-strain rate compressive behavior of concrete made with substituted coarse aggregates: recycled crushed concrete and clay bricks," Construction and Building Materials, vol. 301, 2021.

[5] C. Liang, J. Xiao, C. Wang, and Z. Ma, "Hysteretic energy and damping variation of recycled aggregate concrete with different cyclic compression loading levels," Journal of Building Engineering, vol. 44, 2021.

[6] W. Mahmood, A. Khan, and T. Ayub, "Mechanical and durability properties of concrete containing recycled concrete aggregates," Iranian Journal of Science and Technology, vol. 6, 2021.

[7] J. Zhang, Li Cheng, Le Ding, and Li Jian, "Performance evaluation of cement stabilized recycled mixture with recycled concrete aggregate and crushed brick," Construction and Building Materials, vol. 296, 2021.

[8] F. Xie, J. Li, G. Zhao, C. Wang, Y. Wang, and P. Zhou, "Experimental investigations on the durability and degradation mechanism of cast-in-situ recycled aggregate concrete under chemical sulfate attack," Construction and Building Materials, vol. 297, 2021.

[9] M. Sabău and J. R. Duran, "Prediction of compressive strength of general-use concrete mixes with recycled concrete aggregate," International Journal of Pavement Research and Technology, vol. 15, 2021.

[10] K. Saied, O. Zoltan, and C. Oliver, "The influence of utilizing recycled and reclaimed coarse aggregates in producing concrete for structural applications," Tehnički Vjesnik, vol. 28, no. 3, 2021.

[11] C. Du, J. Luo, and L. Jia, "Review on the application of recycled concrete," Shanxi Architecture, vol. 42, no. 7, pp. 109-110, 2016.

[12] J. Guo, S. Liang, Q. Zhang, and Z. Xiao, "Study on factors influencing the dry shrinkage performance of low alkalinity sulphate aluminate cement," China Cement, vol. 1, no. 1, pp. 8-11, 2010.

[13] Z. Xie, Z. Li, and J. Lu, "Research status and development suggestions of green concrete," Recyclable Resources and Circular Economy, vol. 12, no. 2, pp. 36-39+44, 2019.

[14] L. Song and D. Yang, "Discussion on the application of recycled coarse aggregate in low strength grade concrete," Guangdong Building Materials, vol. 9, no. 9, pp. 47-49, 2017.

[15] T. Wang, S. Cheng, and F. Xu, "Discussion on shrinkage and creep performance of recycled concrete in different aggregate grades," Metallurgical Collections, vol. 3, no. 1, p. 13, 2017.

[16] R. Li, Study on Preparation and Performance of Vegetated Ecological ConcreteSouth China University of Technology, Guangzhou, China, 2009.

[17] E. A. B. Koenders, Simulation of Volume Changes in Hardening Cement-Based materials, pp. 97-99, Delft University Press, Delft, Netherlands, 1997.

[18] Z. Meng, Z. Wu, and J. Qian, "Alkalinity of pore fluid of highaddition flyash concrete," Journal of Chongqing Jianzhu University, vol. 21, no. 1, pp. 24-27, 1999. 
[19] L. Liang, H. Yu, and Z. Pan, "Actual mesostructure-based three-dimensional reconstruction of porous concrete," Journal of Hohai University (Natural Sciences), vol. 38, no. 4, p. 427, 2010.

[20] Y. Zhou, "Determination and calculation of specific surface area of concrete aggregate," Concrete, vol. 2, pp. 48-51, 1984.

[21] Y. Li and X. Hu, "Designing of previous concrete mixture proportion by surrounding spherical model," Concrete, vol. 227, no. 9, pp. 29-32, 2008.

[22] N. Feng, New Practical Concrete Collection, Science Press, Beijing, China, 2005.

[23] X. Pan, Study on Preparation Method and Properties of Porous Cement Concrete Pavement MaterialsChang'an University, Xi'an, China, 2010.

[24] L. Mao, The Mechanics Analysis of Vegetation Root in Ecology Slope Protection, Wuhan University of Technology, Wuhan, China, 2007.

[25] J. Dong, Y. Pei, and L. Wang, "Research and practice of environmental friendly greening concrete," Jilin Water Resources, vol. 2, no. 2, pp. 1-4, 2002.

[26] Z. Liu and C. Lu, Study on the Cementitious Materials with Low Alkalinity for Environmentally Friendly ConcreteNanjing Hydraulic Research Institute, Nanjing, China, 2004.

[27] J. Wei, "Study on application of ecological concrete technology," Communications Science and Technology Heilongjiang, vol. 4, no. 4, pp. 1-2, 2010.

[28] W. Tian, "Reflect over composition of comprehensive harness plan for soil and water conservation on road construction programme," Bulletin of Soil and Water Conservation, vol. 20, no. 3, pp. 31-34, 2000.

[29] Z. Xu, R. Liao, and C. Lou, "Control measures of non-point source pollution in urban river areas," Beijing Water, vol. 5, no. 5, pp. 26-28, 2005.

[30] W. Liang, A. Chen, and C. Yu, "Performance research and engineering application of recycled aggregate oncrete," Guangdong Building Materials, vol. 8, no. 8, pp. 18-20, 2017. 